\title{
Vergilemede Yasalık İlkesinin Danıştay 3. Daire Kararı Işığında Hukuksal ve Nitel Analizi
}

\author{
Filiz EKINCII \&Şebnem EKERYILMAZ $\dot{I}^{1}$
}

$\ddot{\mathbf{O z}}$

Yasallık ilkesi Anayasamızın 73. maddesinin 3. fikrasında açıkca hüküm altına alınmıştır. Bunun yanında Anayasamızın 38. maddesinde de suç ve cezalarda yasallık ilkesinin geçerli olacağ hüküm altına alınmıştır. İlgili hükümlere bağlı olarak yasallık ilkesinin vergileme hususunda uygulanması keyfi değil anayasal bir zorunluluktur. Yasallık ilkesi; vergilerin kanunla konulup, kaldırılıp, değiştirilmesinin yanında vergilendirme sürecinde yer alan tüm idari işlemlerinde kanunlara dayanılarak yapılmasını gerektirmektedir. Bu çalışmanın konusunu, vergileme açısından önemli olan yasallık ilkesinin; Danıştay 3. Daire Kararı çerçevesinde hukuksal ve nitel analizinin yapılarak ilkenin derinlemesine incelenmesi oluşturmaktadır. İlgili kararın seçilmesinin gerekçesini yasallık ilkesine vurgu yapması ve ilke dikkate alınarak karar verilmesi oluşturmaktadır.

Anahtar Kelimeler: Vergilemede Yasallık İlkesi, Danıştay 3. Daire Kararı, Hukuksal Analiz.

JEL Kodları: K34

\section{Legal and Qualitative Analysis of the Principle of Legality in Taxation in the Light of the Third Chamber Decision of the State Council}

\begin{abstract}
The principle of legality is clearly stipulated in parafraph 3 of Article 73 of our Constitution. In addition, Article 38 of our Constitution stipulates that the principle of legality will be valid in crimes and penalties. The application of the principle of legality on taxation in accordance with the relevant provisions is not arbitrary but a constitutional obligation. Principle of legality; Besides, it requires the law to be made, abolished and amended by law, and all administrative procedures taking place in the taxation process. The aim of this study is the principle of legality which is important in terms of taxation; The Council of State has made a legal and qualitative analysis within the framework of the 3rd Chamber Decision and an in-depth examination of the principle. The reason for choosing the relevant decision is to emphasize the principle of legality and to make a decision based on the principle.
\end{abstract}

Keywords: The Principle of Legality in Taxation, 3rd Chamber Decision of the Council of State, Legal Analysis.

JEL Classification Codes: K34

\footnotetext{
${ }^{1}$ Doç. Dr., filiz.ekinci@bilecik.edu.tr

${ }^{2}$ Arş. Gör., sebnem.ekeryilmaz@bilecik.edu.tr
} 


\section{Giriş}

Yasallık ilkesi Anayasanın 73. maddesinde; "Vergi, resim, harç ve benzeri yükümlülükler kanunla konulur, değiştirilir veya kaldırılır." şeklinde hüküm altına alınmıştır. Anayasal hüküm biçimsel olarak sadece verginin kanunla konulup kaldırılmasını veya değiştirilmesini hüküm altına alsa da içerik olarak yorumlandığında vergilemeye ilişkin bütün unsurların kanunlara dayanılarak yapılmasını gerektirmektedir. Yasallık ilkesinin temel amacı vergilendirmede keyfiliğin önlenmesidir. Vergilendirme alanında yasallık ilkesinin önemli olmasının gerekçesini de bu durum oluşturmaktadır. Vergilendirme kişilerin gelirlerinin bir kısmının kamu yararı amacıyla devlete aktarılması ve kamu hizmetlerinin finansmanında kullanılmasını gerektirdiğinden keyfi olarak kullanılmaması büyük önem taşımaktadır. Yasallık ilkesinin ihlal edilmesi mükelleflerin vergi ödememesine sebep olurken, devletin de vergi gelirlerinin azalmasına yol açacaktır.

Anayasa Mahkemesi Kararında da; yasallık ilkesinin evrensel düzeyde kabul gören hukukun üstün kurallarında olduğu ve evrensel hukuk ilkelerinden biri olduğu yer almıştır (Anayasa Mahkemesi'nin 27.2.2014 tarihli ve E. 2012-87, K. 2014-41 sayılı kararı).

Bu çalışmanın amacını; Anayasada hüküm altına alınan yasallık ilkesinin teorik olarak incelenmesinin yanında ilkeye ilişkin olan Danıştay 3. Daire Kararının hukuksal ve nitel analizinin ${ }^{1}$ yapılarak ilkeyi olumsuz etkileyen hususların tespit edilmesi ve çözüm önerileri getirilmesi oluşturmaktadır.

Çalışmada öncelikle yasallık ilkesi teorik olarak incelenerek, yasallık ilkesine ilişkin Danıştay 3. Daire Kararının hukuksal analizi yapılmıştır. Daha sonra yasallık ilkesine ilişkin Danıştay 3. Daire Kararının nitel analizi yapılarak, sonuç bölümünde hukuksal ve nitel analiz sonucunda elde edilen hususlar değerlendirilerek ve çözüm önerileri getirilmiştir.

\section{Yasallık İlkesinin Teorik Olarak İncelenmesi}

Yasallık ilkesinin kelime anlamı bir durumun kanunlara uygunluğudur. Bu kullanım şekli her ne kadar şekli anlamda kanuna referans yapar gibi görünse de, yasallık ilkesi yürürlükteki mevcut hukuk kurallarının tümünü kapsayan bir niteliğe sahiptir (Altındağ 2016: 3o).

Vergi hukukunun kanuni düzenlemelerin en kapsamlı olduğu hukuk kolu olması sebebiyle yasallık ilkesi bu alanda önem kazanmaktadır. Vergilemede yasallık ilkesi; Anayasamızda yer alan bireylerin hak ve özgürlüklerinin korunmasında özel önem arz eden, güvence ve istikrar gerektiren konulara ilişkin olan ve hukuk devleti ilkesinin gerekliliklerinden doğarak kamu hukuku ve anayasa hukukunun şekillendirdiği pekiştirici nitelik taşıyan ana ilke konumundadır (Güneş 2014: 7).

\footnotetext{
${ }^{1}$ Nitel analiz NVivo 12 programı aracılığıyla yapılımıştır.
} 
Vergilendirmeye ilişkin yetkinin yasama organına ait olmasını sağlayan yasallık ilkesinin sonuçlarından birisi de yasama organının vergi kanunu çıkarmadan önce vergiden bahsedilmemesi ve devlet ile mükellef arasında vergi ilişkisinin doğmamasıdır. Yasama organının haricinde, başka hiçbir organın vergi koymaya ilişkin yetkisi olmadığından verginin bütün unsurlarıyla birlikte yürürlüğe konulacak şekilde kanunla belirlenmesi gerekmektedir (Tekbaş 2009: 246).

Yasallık ilkesi aracılığıyla devletin keyfiliği önlenmekte ve bu sayede devamlılığ1 sağlanmaktadır. Kuvvetler ayrılığı prensibide yasallık ilkesi aracılı̆̆ıyla sağlanmaktadır (Evren 2011: 976).

Yasallık ilkesi, bir yandan vergilendirme yetkisini kullanan devlete bağlayıcı bir sınır çizerken, öte yandan yükümlüler açısından da kanunilik ilkesinin ihlali halinde buna karşı çıkmak için haklar tanımaktadır. Yasallık ilkesi, vergilerin kanunlara uygun ve doğru olarak alınmasını da içermektedir (Kumrulu, 1979: 150-151).

1215 tarihli Magna Carta yasallık ilkesi açısından büyük önem arz etmektedir. Magna Carta'da parlamentonun izni olmadan vergilerin alınamayacağı anlamına gelen kanunilik ilkesi yer almıştır (Tomkins 2010: 41).

Yasallık ilkesi ülkemizde anayasal süreçte; 1924 Anayasası'nın 85. maddesinde “Vergilerin ancak bir kanun ile tarh ve cibayet olunabilir." şeklinde yer alırken, 1961 Anayasası'nın 61. maddesinde "Vergi, resim, harçlar ve ve benzeri mali yükümlülükler ancak kanunla konulur." şeklinde yer almıştır. 1982 Anayasasında ise kanunla konulmasına ilave olarak, kaldırılması ve değiştirilmesinin de kanunla yapılabileceği ifade edilmiştir (Öz ve Akçay 2012: 161).

Yasallık ilkesi açısından diğer önem arz eden husus ise yargı organlarının ilkeye uyumlu hareket etmesidir. Yasallı ilkesinin denetiminin yarg1 organları ile yapılması sebebiyle vergilendirmeye ilişkin işlemleri denetleyen yargı organlarının bağımsız olması ile kanunilik ilkesi sağlanmış olur (Chevallier 2010: 74).

\section{Yasallık İlkesinin Danıştay 3. Daire Kararı Işı̆̆ında Hukuksal Analizi}

Hukuksal analizi yapılacak karar Danıştay 3. Dairesi’nin 2005-391 Esas Sayılı 2005-2639 Karar Sayılı kararıdır. Kararın seçilme gerekçesini ilgili olayda yasalık ilkesi dikkate alınarak karar verilmesi oluşturmaktadır. Hukuksal analize konu olan karara ilişkin süreç aşağıdaki gibidir.

Davacının yasal süresinde verdiği 2001 yılına ilişkin gelir vergisi beyannamesine ek olarak elde ettiği menkul sermaye iradı için 19.4.2004 tarihinde beyanname vermesi üzerine gecikme faizi tahakkuk ettirilmiştir. Davacı tahakkuk ettirilen gecikme faizine aşağıdaki gerekçelerle dava açmıştır.

1. Vergi Usul Kanununun 341. ve 344. maddelerine dayanılarak verginin süresinde tahakkuk ettirilmediği için vergi ziyaı cezası kesilmesini gerektirmesi, 
2. Vergi Usul Kanunun 112. maddesinde düzenlenen gecikme faizinin ancak ikmalen, resen veya idarece tarh edilen vergiler için tahakkuk ve tahsil edilebileceğidir.

Vergi mahkemesi; gecikme faizi ve gecikme zammı oranının aynı olması sebebiyle hukuka aykırılık olmadığı gerekçesiyle davayı reddetmiştir (Vergi Mahkemesi'nin 27.10.2004 tarih ve E. 2004-137, K. 2004-303 say1l karar1).

Vergi mahkemesinin davayı reddetmesi üzerine yükümlü; verginin yorumla alınmasının yasallık ilkesine aykırı olduğu ve ikmalen, resen veya idarece yapılmış tarhiyat olmaksızın gecikme faizi tahakkuk ettirilmesinin yasallık ilkesini ihlal ettiği gerekçesiyle Danıştay 3. Dairesine temyiz isteminde bulunmuştur.

Danıştay 3. Dairesi; Vergi Usul Kanunun 112. maddesini göz önünde bulundurarak ikmalen, resen veya idarece yapılan bir tarhiyat bulunmadığı için gecikme faizi tahakkuk ettirilmesini yasallık ilkesine aykırı bularak verilen kararın hukuka uygun olmadığı yönünde karar vererek vergi mahkemesinin kararını bozmuştur.

Yasallık ilkesi vergilerin kanunla konulmasının yanında vergilendirmeye ilişkin işlemlerde de yasallık ilkesinin uygulanmasını gerektirmektedir. Gecikme faizi ve zammı birbirinden nitelik olarak farklıdır. Benzerlikleri sadece oranlarının aynı olmasından kaynaklanmaktadır.

Gecikme zammı ve gecikme faizinin birbirinden farklı olduğu hususlar aşağıdaki gibidir (Gerçek, 2017: 98).

-Gecikme zammı, vadesi geçmiş olan tüm kamu alacaklarına uygulanırken, gecikme faizi, ikmalen, resen veya idarece tarh edilen vergilere uygulanmaktadır.

-Gecikme zammı, tahsil aşamasında vade tarihinden ödemenin yapıldı̆̆ 1 tarihe kadar uygulanırken, gecikme faizi, tahakkuk aşamasında kanuni vade tarihinden tahakkuk tarihine kadar uygulanmaktadir.

-Gecikme zammının hesaplanmasında ay kesirleri dikkate alınırken, gecikme faizinin hesaplanmasında ay kesirleri dikkate alınmamaktadır.

-Gecikme zammını durduran ve sona erdiren haller mevcut iken gecikme faizinde ilgili haller söz konusu değildir.

Yukarıdaki karşılaştırma dikkate alındığında gecikme zammı ve gecikme faizinin arasında ciddi farklılıkların olduğu görülmektedir. Ay kesirlerinin hesaplanmasında bile farkl1l1klar bulunan gecikme zammı ve gecikme faizinin, oranlarının aynı olması sebebiyle birbirinin yerine tercih edilebilir duruma getirilmesi yasallık ilkesinin ihlali anlamına gelmektedir. Kanunda ayrı düzenlenmiş olan iki müessesesin varllğı̆ın mevcut olması kanunda boşluk olmadığının da göstergesidir. Vergi hukukunda kanunda boşluk olması durumunda dahi kıyas yasağı ve kanunilik ilkesi gereğince yargı 
yorumu ile boşluk doldurulmasına izin verilmezken, kanunda boşluk olmadığında böyle bir yetkinin yargı organları tarafından kullanılması yasallık ilkesini ağır derecede zedelemektedir. Bu gerekçelerle yasallık ilkesi dikkate alınarak verilen Danıştay 3. Dairesi'nin kararının yerinde olduğu düşüncesindeyiz.

\section{Yasalık İlkesinin Danıştay 3. Daire Işı̆̆ında Nitel Analizi}

Aşağıda yasallık ilkesine ilişkin Danıştay 3. Dairesi kararında en sık kullanılan kelimelerin bulut dökümü ve tablo dökümü yer almaktadır. Kelime bulutu dökümüne baktığımızda hukuksal analiz ile paralel olarak "gecikme faizi" ve "gecikme zammı", "kanunilik" ve "yasal" kelimelerinin metin içinde kullanıldığı görülmektedir.

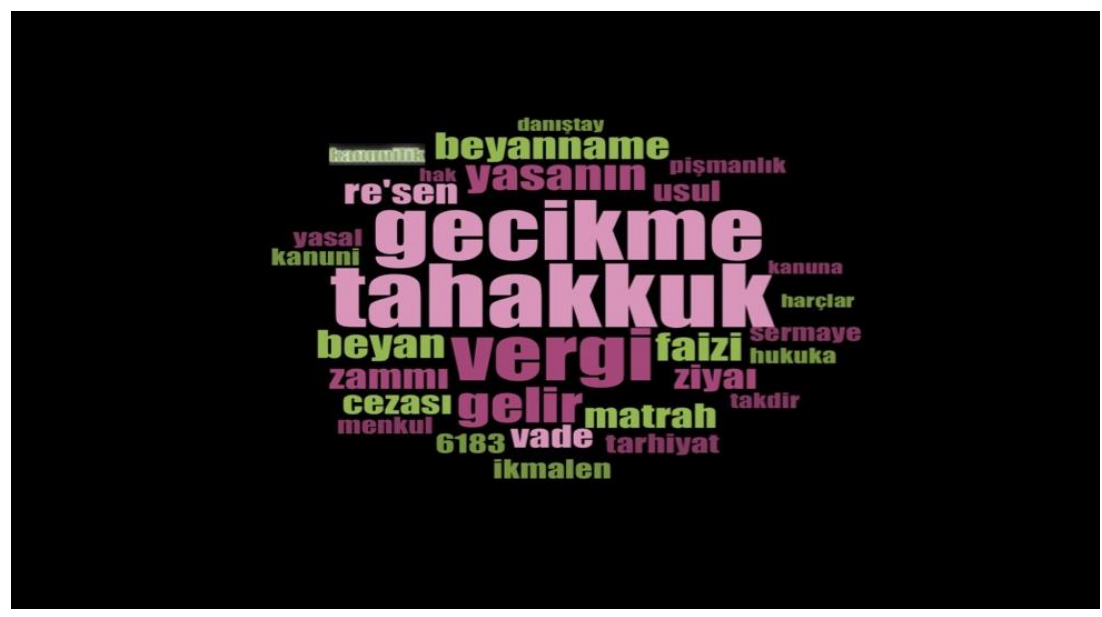

Şekil 1. Danıştay 3.Daire Kararında En Sık Kullanılan Kelimelerin Bulut Dökümü

Tablo 1. Danıştay 3. Dairesi Kararında En Sik Kullanılan Kelimelerin Tablo Dökümü

\begin{tabular}{|l|r|r|}
\hline & Kullanım Sayısı & \multicolumn{2}{|c|}{ Kullanım Yüzdesi } \\
\hline tahakkuk & 28 & $7,24 \%$ \\
\hline gecikme & 26 & $6,72 \%$ \\
\hline vergi & 22 & $5,68 \%$ \\
\hline gelir & 13 & $3,36 \%$ \\
\hline yasanın & 10 & $2,58 \%$ \\
\hline beyan & 9 & $2,33 \%$ \\
\hline faizi & 9 & $2,33 \%$ \\
\hline beyanname & 8 & $2,07 \%$ \\
\hline matrah & 7 & $1,81 \%$ \\
\hline re'sen & 7 & $1,81 \%$ \\
\hline zammı & 7 & $1,81 \%$ \\
\hline ziyaı & 7 & $1,81 \%$ \\
\hline
\end{tabular}




\begin{tabular}{|l|r|r|}
\hline cezası & 6 & $1,55 \%$ \\
\hline vade & 6 & $1,55 \%$ \\
\hline usul & 5 & $1,29 \%$ \\
\hline 6183 & 4 & $1,03 \%$ \\
\hline ikmalen & 4 & $1,03 \%$ \\
\hline tarhiyat & 4 & $1,03 \%$ \\
\hline kanuni & 3 & $0,78 \%$ \\
\hline menkul & 3 & $0,78 \%$ \\
\hline sermaye & 3 & $0,78 \%$ \\
\hline yasal & 3 & $0,78 \%$ \\
\hline hukuka & 2 & $0,52 \%$ \\
\hline pişmanlık & 2 & $0,52 \%$ \\
\hline takdir & 2 & $0,52 \%$ \\
\hline danıştay & 1 & $0,26 \%$ \\
\hline hak & 1 & $0,26 \%$ \\
\hline harçlar & 1 & $0,26 \%$ \\
\hline kanuna & 1 & $0,26 \%$ \\
\hline kanunilik & 1 & $0,26 \%$ \\
\hline
\end{tabular}

Kaynak: Tablo nitel analiz aracılı̆̆ıyla tarafımızca oluşturulmuştur.

Danıştay 3. Daire kararının içerik analizinin tablo dökümünden hareketle; ilgili kararda en sık kullanılan kelimenin \%7.24 metin içi yüzdesiyle tahakkuk olduğu görülmektedir. Yasal ve kanuni kelimesi $\% 0.78$ oranla, kanunilik ilkesi de \%0.26 metin içi kullanım yüzdesiyle kararda yer almıştır. İlgili durum kararın yasallık ilkesi dikkate alınarak verildiğinin göstergelerinden birisidir.

\section{Sonuç ve Öneriler}

Kanunilik ilkesi hukuki nitelik olarak, Anayasada hüküm altına alınan bir ilke olması sebebiyle uygulanması keyfi değil zorunlu olan bir ilkedir. İlgili durum ilkenin vergilendirmeye ilişkin idari işlemlerde ve yargı kararlarında da dikkate alınması sonucunu doğurmaktadır.

Çalışmamızda kullanılan analizler birbirini destekler niteliktedir. İçerik analizi sonucunda en sık kullanılan kelimeler dikkate alındığında; "yasal", "kanuni" ve "kanunilik" kelimelerinin metin içinde sıklıkla kullanıldığı tablo dökümü ve bulut dökümünden açıkça görülmektedir. Nitel analiz sonuçları da hukuksal analizi destekler şekilde yargı kararında kanunilik ilkesinin dikkate alındığı yönündedir.

Hukuksal analizi yaptığımız yargı kararında, vergi mahkemesinin, yasallık ilkesini göz önünde bulundurmayarak sadece oranlarının benzeşmesi sebebiyle gecikme zammı ve gecikme faizinin 
birbirine tercih edilebileceği yönünde karar vermesi üzerine, 3. Daire yasallık ilkesi gereğince vergi mahkemesinin kararını bozmuştur.

Vergi hukukunda kanunilik ilkesinin var olması sebebiyle ekonomik yaklaşım ilkesinin sınırını kıyas yasağı oluşturmaktadır. Ekonomik açıdan bakıldığında oranlarının aynı olması gerekçesiyle, hazineye intikalinde tutar açısından bir fark bulunmasa da yasallık ilkesi ihlal edilmektedir ki hesaplanmasında gecikme zammında ay kesirlerinin dikkate alınması sebebiyle vergi tutarında da farklılığın ortaya çıkması muhtemeldir. Dava konusu olayda yasallık ilkesinin ihlal edilmesi aynı zamanda kıyas yasağının da ihlali anlamına gelmektedir. Kanunda mevcut düzenlemenin bulunması ve boşluk olmaması durumunda ilgili düzenlemeye sadık kalınması yasallık ilkesinin gerekliliklerindendir.

Soyut olan vergileme ilkelerin yargı kararları ve vergilendirmeye ilişkin işlemlerde göz önünde bulundurulması büyük önem taşımaktadır. Bu nedenle yargı organlarınca ve idarenin tesis ettiği işlemlerde temel ilke olan yasallık ilkesinin ve diğer vergileme ilkelerinin dikkate alınması mükellefleri vergisini ödemeye teşvik ederken, devletin de vergi gelirlerinin artması sonucunu doğuracaktır.

\section{Kaynakça}

Altındağ, Halil (2016) İdarenin Yargısal Denetiminde Kanunilik Blokunun Genişlemesi, On İki Levha Yayınc1l1k, İstanbul.

Çağan, Nami (1980) "Demokratik Sosyal Hukuk Devletinde Vergilendirme", Ankara Üniversitesi Hukuk Fakültesi Dergisi, 37(1-4), ss.129-151.

Chevallier, Jacques (2010), Hukuk Devleti (Çev. Ertuğrul Cenk Gürcan), Ankara, İmaj Yayınevi.

Gerçek, Adnan (2017), Kamu Alacaklarının Tahsil Hukuku, (5. baskı), Ekin Yayın, Bursa.

Evren, Çınar Can (2011) “Kabahatlerde Kanunilik İlkesi”, İstanbul Üniversitesi Hukuk Fakültesi Mecmuası, 12, ss. 967-1002.

Güneş, Gülsen (2014) Verginin Yasallı̆̆ı İlkesi, (4. baskı), On İki Levha Yayıncılık, İstanbul.

Kumrulu, Ahmet (1979) "Vergi Hukukunun Birkısım Anayasal Temelleri”, Ankara Üniversitesi Hukuk Fakültesi Dergisi, 36(1), ss. 147-162.

Tekbaş, Abdullah (2009) Vergi Kanunlarının Anayasaya Uygunluğunun Yargısal Denetimi, Maliye Bakanlı̆̆ı Strateji Geliştirme Başkanlığı, Yayın No: 2009/396, Ankara.

Tomkins, Adam (2010) Public Law, Clarendon Law Series, Oxford University Press, UK.

Öz, Ersan ve Akçay, Fatih (2012) "Uygulama ve Örnekleriyle Türk Vergi Hukukunda Gerçek ve Gerçek Olmayan Geriye Yürümeler ve Hukuki Güvenlik İlkesine Etkisi”, Vergi Sorunları Dergisi, 288, ss. 160174.

Anayasa Mahkemesi'nin 27.2.2014 tarihli ve E. 2012-87, K. 2014-41 sayıll kararı.

Danıştay 3. Dairesi'nin 2.12.2005 tarih ve E. 2005-391, K. 2005-2639 sayılı kararı.

Vergi Mahkemesi'nin 27.10.2004 tarih ve E. 2004-137, K. 2004-303 sayıl1 kararı. 